\title{
Don Juan Huarte de San Juan: El doctor que anticipó la melancolía de Don Quijote
}

\author{
Don Juan Huarte de San Juan: \\ The doctor who anticipated Don Quixote's Melancholy
}

\section{Pedro García Martín}

Profesor titular de Historia Moderna de la Universidad Autónoma de Madrid. España.

\section{Correspondencia:}

Pedro García Martín

Profesor Titular de Historia Moderna

Facultad de Filosofía y Letras

Universidad Autónoma de Madrid

Ciudad Universitaria de Cantoblanco

Ctra. De Colmenar Viejo, 15.

28049 Madrid. España.

pedro.garcia vam.es

Resumen

El estado de enajenación del ingenioso hidalgo don Quijote lo había aprendido Cervantes a través del doctor Juan Huarte San Juan, autor del famoso ensayo Examen de ingenios, donde formula la teoría de los humores para explicar el cuerpo y el carácter del hombre. En este artículo, pues, repasaremos la biografía de este personaje, analizaremos la formación de los médicos en las universidades de la España del Siglo de Oro, la influencia del Examen en la Europa de su tiempo y en la obra cervantina a través de la melancolía de don Quijote y de la locura del Licenciado Vidriera. Para terminar con la aplicación literaria de las tesis sobre ingenios que definiera nuestro dilecto médico de resonancia mundial.

Palabras clave: Historia moderna, Historia de la medicina, Médicos famosos, El Quijote, Juan Huarte de San Juan, Med Segur Trab 2009; 55 (214): 119-131

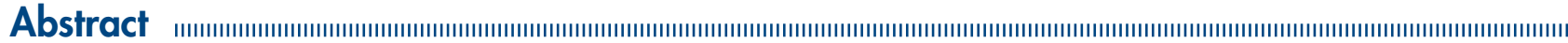

Cervantes learned about Don Quixote's derangement through Juan Huarte de San Juan's famous treatise Examen de ingenios, where he deployed the humoral theory to explain human body and character. In this article Huarte's biography will be summarized, analyzing the academic background of golden age Spanish doctors, and the impact of Examen in Early Modern Europe and in Cervante's work by examining Don Quixote's melancholy and Licenciado Vidriera's madness. Finally, I will show how the internationally famous Spanish doctor's thesis was used in literature.
\end{abstract}

Key words: Early Modern History, History of Medicine, Famous Doctors, The Quixote, Juan Huarte de San Juan, Med Segur Trab 2009; 55 (214): 119-131 
"De manera que el rezar, contemplar y meditar enfría y deseca el cuerpo y lo hace melancólico... Hasta caer en manía, que es una destemplanza caliente y seca del celebro".

Juan Huarte De San Juan Examen de ingenios. Baeza, 1575, cap. V.

"Era (Don Quijote de la Mancha) de complexión recia, seco de carnes, enjuto de rostro, gran madrugador y amigo de la caza... Y del poco dormir y del mucho leer, se le secó el celebro de manera que vino a perder el juicio".

Miguel de Cervantes El Ingenioso Hidalgo Don Quijote de la Mancha. Madrid, 1605, I, cap. 1.

No hay que avanzar mucho en la obra cumbre de la literatura española para aparejar casa, familia y condición del protagonista. En realidad, en la primera página de El Quijote se nos sitúa en un lugar, lo que significa una aldehuela o sitio pequeño, para trazar de seguido una radiografía personal del aspirante. Las armas de sus antepasados entronizadas entre el mobiliario. La dieta semanal de cristiano tan viejo como pobre. La indumentaria estamental para diario y fiestas de guardar. El número y calidad de los miembros de su hogar y familia. El ocioso ejercicio de la caza, mediante galgo corredor, como sucedáneo de la guerra. La edad provecta del protagonista, y, sobremanera, su constitución física proclive al humor colérico. Porque esta sintomatología, tenida por científica en la época, había sido anticipada por el doctor Juan Huarte de San Juan en su afamada obra Examen de ingenios.

En esta universidad casera, pues, nuestro héroe andante cursará estudios, teniendo por manuales libros de caballería, por prácticas los arreglos de la armadura oxidada. En ese rincón de su mansión y su cabeza, ambas perdidas del mundo, adquirirá por compañeros un rocín metafísico y un escudero ganapán. Al cabo, saldrá al estrado de La Mancha, y, tras denodada porfía en la que no faltaron pedradas de arrieros durante la imaginaria, el hidalgo se licenciará al ser armado caballero por el castellano de una venta. Nacía el mito del hidalgo manchego.

Ahora bien, el estado de enajenación lúcida de don Quijote, lo habían aprendido los hombres de letras de la Europa del Barroco, entre otros, a través del ensayo del doctor San Juan. El primer tratado, escrito en lengua vernácula, de lo que Roger Bartra llama "las enfermedades del alma” es El libro de la melancolía del español Andrés Velásquez (1585). Al que le sigue $A$ Treatise of Melancholy de Timothy Bright, publicado en Londres en 1586, que tanto va a influir en el Hamlet de Shakespeare. Y a éste, las Meditaciones de René Descartes, donde el filósofo francés define la llamada "locura vítrea" de amplias resonancias literarias. $\mathrm{Y}$ aunque estos ensayos posteriores critiquen los paradigmas del Examen de ingenios, no dejan de ser deudores de la teoría del "ingenio" que cada hombre dispone para el ejercicio de las actividades.

De manera que a las tres diferencias de ingenio cuantitativas, que el autor navarro llama "grados de habilidad", le corresponden otras tantas potencias racionales (la memoria, la imaginativa y el entendimiento) de las que dependen. Por eso, aquellos que son brillantes en las letras y en las ciencias, se pueden mostrar torpes en otros menesteres, y viceversa.

En este artículo, pues, repasaremos la biografía plena de lagunas del doctor Huarte de San Juan, analizaremos la formación de los médicos en las universidades de la España áurea, la influencia del Examen en la obra cervantina a través de la melancolía de don Quijote y de la locura del Licenciado Vidriera, para terminar con la aplicación literaria de las tesis sobre ingenios y humores que definiera nuestro dilecto médico. Para concluir en 
la idea común que el mucho leer y poco dormir enfría el cuerpo, su destemplanza hace caer en manía, hasta que se seca el cerebro y se pierde el juicio. El diagnóstico de un médico precoz que, avant la lettre, predijo la melancolía quijotesca.

\section{UNA BIOGRAFÍA LLENA DE LAGUNAS}

La biografía de nuestro personaje está llena de lagunas. De entrada, como nos señala Guillermo Serés, él mismo emplea varias firmas, unas veces “doctor Juan de San Juan”, otras "doctor Juan Huarte de San Juan", en los menguados rastros documentales que ha dejado. Sabemos que nació, alrededor del año 1529, en la villa de San Juan del Pie del Puerto, capital de la sexta merindad del reino de Navarra, que por entonces pertenecía legalmente a la Corona hispana. Este estatus político se mantendrá hasta que en 1660, merced a la paz de los Pirineos, la comarca pase a jurisdicción francesa. De manera que envuelta en estos litigios fronterizos, así como reconocida sus probanzas de hidalguía, la familia del futuro autor del Examen emigró a la ciudad andaluza de Baeza, donde será conocido como doctor San Juan.

A partir de aquí proliferan las inexactitudes. Algunos autores sostienen que su familia se estableció, antes de 1540, en Baeza, donde Huarte cursaría la licenciatura en artes en el colegio-universidad de aquélla ciudad humanista. Otros, como A. Chinchilla en sus Anales bistóricos de la medicina (1841) y A. Hernández Morejón en su Historia bibliográfica de la medicina española (1843), se limitan a afirmar que estudió medicina en Huesca, donde apellidos como Huart, Hugart o Hugarte figuran en los registros universitarios del momento. Sin embargo, lo que parece más probable es que lo hiciese en Alcalá de Henares, en cuyos libros de matrícula aparece un nombre similar al de nuestro protagonista entre los años 1553 y 1559. Allí asistiría a las clases de prestigiosos profesores, como Andrés Laguna, López de Corella o Francisco Vallés, consiguiendo al cabo de seis años el grado de doctor.

Lo que sí está acreditado es que en 1571 firmó un contrato con el concejo de Baeza, a fin de atajar la peste que afectaba a la villa, "a causa de haber muerto en la dicha ciudad todos los médicos viejos y de espiriencia...", y porque "era hombre de muchas letras...". Todo ello lo sabemos con certeza a través de una Real Provisión de 1572 donde el Concejo, Justicia y Regimiento de Baeza solicita al monarca ajustar los servicios profesionales del ilustre médico, lo que demuestra que no sólo era un teórico de la materia sino que la ejercitaba. Tal como reza el documento:

"Don Phelipe, por la gracia de Dios, Rey de Castilla, de Aragón...., por qunto por parte de vos el concejo justicia y regimiento de la çiudad de Baeza nos a sido fecha relaçión diziendo a causa de ser aver muerto en esta dicha çiudad todos los medicos viejos y de espiriencia que en ella avia, y no quedar sino medicos moços, y que no thenian espiriencia en su oficio, por el bien y salud de los vecinos desa dicha çiudad y que fuesen mejor curados, aviamos tratado de traer a esa dicha çiudad un medico cual convenia, y ansi aviades traído al doctor Juan de San Juan, que era persona tal cual convenía a la dicha çiudad y vecinos de ella...”.

Sin embargo, aunque Felipe II autorizó prorrogar su contrato por dos años más, dados sus éxitos facultativos, este salario no sacó al doctor ni a su familia de la medianía económica, pues como hace notar Esteban Torre, llaman la atención los exiguos bienes que deja en su testamento: una casa en Linares, un batán y ¡algunas deudas!. El doctor vivirá a caballo entre Baeza, donde los pacientes alababan su "mucha habilidad en curar", y el domicilio "principal" de Linares. Allí había casado 1563 con la paisana doña Águeda de Velasco, también inmigrante navarra, con la que tuvo siete hijos.

El Examen de ingenios, cuya edición fue costeada por el propio doctor e impresa en casa de Juan de Montoya, se editó en febrero de 1575, dedicada "a la Majestad del Rey don Felipe, nuestro señor". Lo que no deja de asombrarnos es que a través de un solo libro se revele uno de los espíritus más finos de nuestra cultura en la transición del Renacimiento al Barroco. Porque el Examen fue objeto inmediato de varias ediciones y 
de su traducción a varias lenguas romances. Y todo ello en vida de Huarte de San Juan, que, como le ocurrirá a Cervantes por razones de pobreza endémica, vio ensombrecidos sus últimos años cuando la Inquisición incluyó la obra en la órbita de sus libros prohibidos.

Conocemos los detalles de su último trance por la bibliografía de Rodrigo Sanz. El 25 de noviembre de 1588 hace testamento en Baeza, "estando enfermo del cuerpo, pero en muy buen seso, juicio y entendimiento natural". En el mismo ordena ser enterrado en la iglesia mayor de Linares, junto a la sepultura de su mujer, nombrándose tras su óbito un procurador para tutelar a sus hijos menores. El último gesto piadoso consistió en fundar una memoria, para que se dijesen nueve misas rezadas cada año por su alma y la de sus difuntos, "perpetuamente para siempre jamás". Una obligación eterna que duró hasta 1720 y cuya práctica se ha perdido por siempre jamás.

La base del tratado de Huarte de San Juan es la anatomía y fisiología del galenismo. Sobre este pedestal clásico, añadió la doctrina de las facultades del alma, que se derivan de la compleción humoral del cuerpo, expuesta por Galeno en su tratado Quod animi mores corporis temperamento sequantur. Aunque, por precaución religiosa, tuvo que introducir abundantes matizaciones para hacerla compatible con los dogmas cristianos de la inmortalidad del alma y el libre albedrío. Pero, sobre todo, el Examen de ingenio para las ciencias nos presenta un método que, basado en el empirismo, sistematiza las habilidades naturales y el ingenio mediante una doctrina por entonces científica. Por tanto, este tratado gira en torno al ingenio o inteligencia, las ciencias o saberes, y la naturaleza, que es lo que hace al hombre hábil para las diversas destrezas. A partir de estos ejes, el doctor San Juan adelanta tres "conclusiones" en sus proemios:

"La primera es que, de muchas diferencias de ingenio que hay en la especie humana, sólo una te puede con eminencia caber... La segunda, que a cada diferencia de ingenios le responde, en eminencia, sola una ciencia y no más... La tercera, que después de haber entendido cuál es la ciencia que a tu ingenio más le responde, te queda ora dificultad mayor por averiguar; y es sí tu habilidad es más acomodada a la práctica que a la teórica”.

De resultas, el volumen aparece dividido en dos grandes partes: la primera, de contenido fisio-psicológico, y la segunda, como un apéndice de la anterior, de temática biológico-dietética. En la naturaleza humana se distinguen "tres grados de habilidad" y "tres diferencias de ingenio". Al primer nivel de habilidad pertenecen los individuos que son capaces de comprender las cuestiones claras y fáciles. Al segundo, los que dominan las reglas y consideraciones del arte, claras y dificultosas, pero a lo que todo se lo han de explicar los buenos maestros. $\mathrm{Y}$ al tercero, unos hombres tan perfectos que no necesitan de maestros, pues son ingenios inventivos. Mas en el plano cualitativo, también descubrimos otros tres niveles de ingenio, pues, según predominen en los individuos las potencias racionales, hallaremos hombres memoriosos, imaginativos e intelectivos. Las diversas categorías se corresponden con un grupo de saberes, pues cada ciencia pide su ingenio: el latín y la gramática pertenecen a la memoria; la dialéctica, al entendimiento, y; la astrología, a la imaginativa.

El siguiente apartado consiste en evaluar esas diferencias de ingenio, que resultan apropiadas para la elocuencia, para el cultivo de la teoría, o la práctica de la teología, el derecho, la medicina y el arte militar, así como para desempeñar el "oficio de rey". La obra termina con un extenso capítulo sobre "la manera cómo los padres han de engendrar los hijos sabios y del ingenio que requieren las letras", que contiene consejos contra la esterilidad, "para conservar el ingenio a los niños después de estar formados y nacidos". Cuando doblamos la última página del tratado, nos llegan los ecos de rabiosa actualidad del discurso huertiano, pues resuena en nuestros oídos el principio de justicia distributiva, según el cual cada individuo debe ocuparse de las tareas para las que está capacitado, en beneficio de sí mismo y del conjunto de la sociedad.

Por último, en este apartado, cabe reiterar el éxito editorial del Examen, el cual hasta el siglo XVIII alcanzó unas ochenta ediciones en siete idiomas: castellano, alemán, francés, 
holandés, inglés, italiano y latín. Y eso que la obra fue incluida en 1583 en el Index librorum probibitorum del Santo Oficio, por mandato del Inquisidor General Gaspar Quiroga, pasando en 1584 al Index librorum expurgatorum, suprimiéndose algunos pasajes. No obstante, las tesis del doctor San Juan contaron con seguidores en todos los países europeos, al considerársele fundador de nuevas disciplinas, como la psicología diferencial y la selección profesional, precursor de la clasificación de las ciencias, así como usuario del método hipotético-deductivo. La otra cara de la moneda es que contó con falsarios e imitadores, como el italiano Antonio Zara (1615) y el español Estaban Pujasol (1637), y que buena parte de sus influencias son meras conjeturas.

En cambio, sí está demostrado que el libro del médico de Baeza se empleó como texto pedagógico en los colegios de la Compañía de Jesús, y que un artículo aparecido en 1712 en la revista The Spectator retoma los principios huertianos para proponer una reforma educativa. $O$ que ha sido consultada por las grandes figuras de la medicina europea e iberoamericana hasta el siglo XIX, como Theophile de Bordeu, Franz Joseph Gall y François Joseph Victor Broussais. Porque, hemos de reconocer que al margen del valor científico de la obra de Huarte de San Juan, estamos ante un texto modélico, en lenguaje y estilo sencillos y elegantes, que le han convertido en un clásico de nuestro Siglo de Oro.

\section{LA FORMACIÓN DE LOS MÉDICOS EN LA ESPAÑA DEL SIGLO DE ORO}

La medicina española vive en el Renacimiento uno de los momentos más brillantes de su historia. Apartándose de la corriente islámica, motejada de "bárbara" por su corrupta traducción de las ciencias clásicas, y bajo la autoridad de Galeno, surge el movimiento del Humanismo médico. La imprenta será su vehículo, la universidad su púlpito, la revisión de los textos su método y los comentarios filosóficos sobre la naturaleza de la medicina sus logros. Tan sólo el oscurantismo de la Contrarreforma empañará esta pujanza de la materia médica en el tránsito al Barroco.

Por eso, desde los Reyes Católicos, la Corona tuteló la formación universitaria de los futuros doctores, así como el ejercicio profesional de la medicina. Para ello, tres Reales Cédulas de 1477, 1491 y 1498, definían la institución del "protomedicato" para examinar a los aspirantes a médicos, cirujanos, especieros y boticarios. De resultas, por la Ley I del Titulo X de la Novísima Recopilación de Leyes, que estará vigente durante el reinado de los Austrias Mayores, Su Majestad delegaba en la universidad la facultad de otorgar el título de medicina y exigía a los examinadores el diploma de bachiller. Desde 1563, los futuros médicos cursaban un bachillerato en artes como requisito previo para ingresar en la Facultad de Medicina, donde deberían dar fe de haber escuchado las tres cátedras de Hipócrates, Galeno y Avicena. En ningún otro país de Europa se exigían tantos requisitos para estudiar la ciencia médica.

La carrera de medicina en la España del Siglo de Oro tenía una duración de cuatro a seis años. Después del grado, la práctica médica se iniciaba al servicio de un doctor reputado, lo que permitía, a la par que un aprendizaje clínico, preparar el examen de "protomedicato" que otorgaba licencia para poder ejercer. Para superar esta prueba, el aspirante se preparaba con el Método Medendi de Galeno como manual, exponiendo su argumentación en latín ante un tribunal, que le hacía preguntas y le observaba en su visita a la sala hospitalaria. Si el futuro "práctico" aprobaba, recibía el título de nomine discrepanti, que daba marchamo de legitimidad a sus estudios.

La vestimenta, dada la importancia social del traje en la sociedad barroca, era instrumental y venía a ensalzar el elevado espíritu del conocimiento médico. De manera que los profesores más prestigiosos, en su mayoría humanistas de honda formación filosófica, portaban traje oscuro, de cuello alto blanco y rizado, así como bocamangas pequeñas. En cambio, los facultativos más modestos usaban un atuendo similar al de los tipos populares, a base de chaleco, casaca y calzones cortos. La misma distinción 
profesional, el contraste de los signos de ostentación pública, llevaba a los superiores a censurar los modos y maneras de los inferiores. De ahí que los médicos afamados, reprochasen a los cirujanos latinos el hecho de llevar un anillo de esmeralda en el pulgar como objeto distintivo, al tiempo que criticaban a los barberos romancistas hablar la jerga del estado llano.

A pesar de este recelo gremial por parte de los maestros, los cirujanos latinos eran muy apreciados por los pacientes al ser expertos en anatomía de los huesos, como los talentosos Valverde de Anueco y Rodríguez de Guevara, que serán figuras modélicas a imitar en Hispanoamérica. En tanto, la categoría de cirujano sangrador, como el propio padre del autor de El Quijote, don Rodrigo de Cervantes, está tan viva en las páginas de la literatura áurea como reales eran sus estrecheces económicas en la vida cotidiana.

Ante las dificultades para hacerse médico, aumentaron los fraudes, en forma de documentación falsa y títulos expedidos por universidades desconocidas. Por eso, en 1563, las Cortes promulgaron una ley por la que sólo podían certificar en medicina las universidades de Salamanca, Valladolid y Alcalá de Henares, expendiendo los profesores del estudiante un certificado para revalidar créditos y graduarse. Acabado el bachiller en medicina, el aspirante debía prestar pasantía durante dos años con un médico reconocido para obtener el diploma, lo que supuso una desventaja para los estudiantes procedentes de un estado bajo al no encontrar un doctor que les aceptase. Más adelante, Felipe II prohibió en 1579 las excepciones a la pasantía, creando tres cargos protomédicos que salían de un tribunal de expertos y fijando un salario digno para los nuevos profesionales. Además, la aplicación de las directrices tridentinas, llevó al monarca a exigir estatutos de limpieza de sangre a los doctores, pues se supone garantizaban la ausencia de herejía. La Corona hispana trasladaría todo este modelo a las posesiones de América y Ultramar.

Por otra parte, uno de los problemas más graves que se presenta para la comunidad médica española era deslindar su labor científica de la práctica de empíricos, hechiceras y romancistas, a pesar del acecho del Santo Oficio. Aunque condenables, los curanderos se defendían jurando que sólo trataban a los enfermos cuando el médico no podía llegar a tiempo, lo que les exculpaba ante el peligro de muerte del paciente. Además, tampoco eran perseguidos con saña, a causa de su gran demanda popular, que no se podía cubrir con solvencia por la falta de médicos. En el fondo también subyacía un prejuicio profesional, pues muchos físicos se negaban a atender a pobres vergonzantes y a acudir a barrios marginales, en los que no les iban a pagar la dieta y sí podían propiciarles algún susto. De tal manera que donde no llegaba la ciencia de los doctores lo hacía la experiencia de los curanderos.

Ahora bien, la principal preocupación del gremio era la salud de la familia real, convertida en asunto de Estado, por lo que menudearon los oficios relacionados con la sanidad que rodeaba al soberano. Durante el reinado de Felipe II se reorganizaron los servicios sanitarios en la Corte. La reforma contempló un nuevo organigrama de doctores al servicio de la Corona, la atención a la farmacia palaciega, la asistencia hospitalaria gratuita a las criadas de la reina a través de la Enfermería de Damas, y la primera mutua sanitaria europea para trabajadores que fue el Hospital Real de Laborantes de El Escorial. De tal manera que los servicios médicos cortesanos comprendían tres organismos: los Oficios de la Real Casa agrupaba a médicos, cirujanos y sangradores; las Clases de la Real Cámara a médicos de cámara, barberos y boticarios, y la Real Cámara de la Reina a enfermeras y enfermeros que atendían a la población femenina de palacio.

A partir de este núcleo médico, el resto del personal sanitario que atendía a la familia del monarca, se ramificaba en una amplia jerarquía de cargos. Los "médicos de cámara en ejercicio" atendían personalmente a los soberanos, visitándolos mañana y noche en sus aposentos, supervisando las comidas y dispensando las medicinas para cada tratamiento. Los "médicos de cámara supernumerarios" gozaban de ese honor por haber sanado a algún miembro de la realeza. Los "médicos de familia en ejercicio" estaban emplazados en los doce cuarteles de la Casa Real. Los "médicos de familia supernumerarios" no tenían destino ni retribución fija. A estos doctores de élite había que añadir seis 
cirujanos, tres sangradores, destiladores y boticarios, que preparaban los medicamentos recetados por los doctores, primero en boticas del común de las ciudades en las que estaba el monarca y desde 1594 en la Real Botica para uso exclusivo de la Corte.

Los especialistas en historia de la medicina española, como Luis Granjel, distinguen tres generaciones de médicos humanistas. La primera, coincidente con el reinado de los Reyes Católicos, contempla distintas escuelas procedentes de los territorios de la corona de Castilla y de la de Aragón. Los castellanos habían sido educados en la tradición arabigoescolástica, menudeando los médicos judíos entre los enfermos privilegiados y los moriscos entre una clientela más popular. Mientras, los aragoneses enlazaban más con las academias romanas, en las que se profesaba el galenismo avicenista, las cuales estaban encaminadas a prestar sus servicios a los Sumos Pontífices.

La segunda hornada, que corresponde a la llegada al trono de Carlos I, es la de los médicos imperiales. Entre estos doctores cortesanos, sobresale Luis Lobera, inseparable en los viajes del Emperador, autor de volúmenes tan apreciados como El banquete de nobles caballeros (1530), el Libro de la Pestilencia (1542) y el Remedio de cuerpos bumanos (1542), donde se respiran los aires del galenismo. Pero también hallamos un prestigioso elenco con nombres como Pedro Carnicer, que atendió al hermano del rey, don Fernando; Francisco Franco, que trabajó para Juan III de Portugal; Fernando López de Escoriaza, que marchó a Londres con la reina Catalina, a los que habría que sumar el prestigioso profesorado de las universidades de Salamanca, Alcalá de Henares y Valencia. Ahora bien, el médico del siglo fue el insigne Andrés Laguna, traductor la castellano del prestigioso Discórides, o Materia Médica de Discórides de Anazarbo, que pasa por ser la obra más importante sobre recursos terapéuticos de la antigüedad clásica. Aunque la fama de erudito de este médico segoviano, anatomista y epidemiólogo, se fue gestando como estudiante en París y docente en Alcalá, profesor itinerante por Europa, físico de la familia real del César Carlos y médico de cámara de los Papas Pablo III y Julio III. El curriculum más brillante de la profesión médica española en el siglo XVI.

Y a la tercera promoción le alcanzan las primeras medidas proteccionistas que, en el campo de la cultura y del control ideológico, se toman al poco de reinar Felipe II. Cuando concluye el Concilio de Trento en 1563, se prohíbe a los estudiantes españoles salir a estudiar a centros extranjeros, estableciéndose un "cordón sanitario" en las fronteras para supervisar el tráfico de ideas y de intelectuales. La Contrarreforma encontró en la institución inquisitorial y en su "Índice de libros prohibidos" la horma de su zapato. Lo que no fue óbice para que en este caldo de cultivo intolerante se fraguase el Examen de ingenios del doctor Juan Huarte de San Juan, y, al cabo de unas décadas, el tratado dejase sentir su ascendiente sobre el ingenio cervantino.

\section{MÉTODO PARA INGENIOS, HUMORES Y MELANCOLÍAS}

En el último acto del siglo XVI, se había superado el relativo desorden de las misceláneas, florilegios y silvas escritos por pensadores renacentistas del talante de Fray Antonio de Guevara, Antonio de Torquemada y Pedro Mexía, para el que los capítulos de un libro no deben seguir un sistema, pues, como sucede en las selvas y bosques, "están las plantas y árboles sin orden ni regla”. Ahora, brota una preocupación enciclopédica pero organicista, en la que un Jerónimo Merola construye "una república del cuerpo humano" y un Pedro Simón Abril ordena el "cuerpo natural" en cuatro apartados, como son el móvil, la cosmología, la generación y el alma. Pues bien, siguiendo a Guillermo Serés, en Huarte de San Juan y en los tratadistas de su generación surge la necesidad de un método de análisis de la naturaleza, que posibilite clasificar los elementos que la componen. En definitiva, un método para ingenios, humores y melancolías.

La influencia del Examen de ingenios en tratadistas posteriores, desde la ciencia médica a la psicología aplicada, se explica por ser a la vez una obra muy original y muy de su época. De manera que su gran difusión, plasmada en sucesivas ediciones y otros 
tantos plagios, viene también por la moda del "ingenio" y del "examen" que se estaba dando en la España del Siglo de Oro. Pues a pruebas de ingenio y a exámenes de habilidad se sometía la discreción de la dama, la calidad del verso en el poeta o la agudeza en los manuales para la educación de los príncipes.

Ahora bien, dado que es recurrente recalcar su carácter de precursor de El Quijote, en este apartado pretendo enjuiciar las relaciones entre el libro del doctor Huarte de San Juan y la obra literaria de Miguel de Cervantes. Debo reconocer que algunos investigadores las han magnificado, como Rafael Salillas, que atisba la presencia de las teorías huertianas desde el calificativo de "Ingenioso Hidalgo" hasta el trastorno mental del caballero andante, la locura cristalina del licenciado Tomás Rodaja y el simbolismo dramático de Persiles y Sigismunda. Esta omnipresencia del médico de Baeza en las novelas del escritor alcalaíno, le llevan a concluir que

“...sin lo que a Huarte se le puede atribuir, que es la definición del tipo de loco, con su forma de locura y sus particulares tendencias, la obra ni pudiera ser, ni habría sido. La eficacia del Examen de Ingenios se demuestra ahora que ya puede decirse que se le debe la concepción del libro más grande y de la figura más original de todas las literaturas".

En realidad, la combinación de humores que postraron a Don Quijote en un estado de melancolía entronca con la tradición medieval, que hablaba de cuatro temperamentos y sus correspondientes signos diferenciales. De forma que el doctor Huarte de San Juan conocía estas doctrinas, así como el libro intitulado Corbacho, escrito a fines del siglo XV por el arcipreste de Talavera, a la sazón Alfonso Martínez de Toledo. En esta sátira sobre las "complexiones" de los hombres, se analizan las disposiciones para el amor según sea el temperamento colérico, sanguíneo, flemático o melancólico. Como también evoca en el Examen su deuda para con los clásicos, del tenor de Galeno, Aristóteles, Hipócrates, Platón y Cicerón, quienes le demostraron que las costumbres del alma siguen el temperamento del cuerpo donde se halle.

Los pensadores del siglo XVI retomarán la teoría de los humores hipocráticos, según la cual la salud o la enfermedad, en los hombres y en las sociedades, dependerán del equilibrio variable de las cuatro sustancias vitales. La correspondencia entre las obras de la naturaleza y las del organismo político es señalada por el señor de Montaigne en sus Ensayos: "por experiencia tocamos y palpamos que la constitución de nuestro ser depende del aire, del clima y del terreno en el que nacemos, y no ya solo el tinte, la estatura, la complexión e inclinaciones, sino también las facultades del alma". De resultas, "las enfermedades y condiciones de nuestros cuerpos se dan también en los estados e instituciones", por lo que, como personas y como súbditos, estamos bajo la influencia de los humores. En esta misma línea, Jean Bodin sostiene en Los seis libros de la República que las condiciones geográficas influyen en la actividad política, por lo que el ciudadano limpio de vicios que le ofusquen la razón "atiende con mayor cuidado a considerar la diversidad de las cosas humanas, la diferencia de las edades, la contrariedad de los humores y la mutación de las Repúblicas, buscando siempre las causas de los efectos que ve".

Más adelante, pues, ya en el siglo XVII, se multiplicarán los efectos comparativos entre la psique y el temperamento de los diversos países. En España, encontraremos a Diego de Saavedra Fajardo anotando que "las costumbres del ánimo siguen el temperamento y disposición del cuerpo", y a Baltasar Gracián afirmando que "participa el agua de las cualidades buenas o malas de las venas por donde pasa, y el hombre de las del clima donde nace". Y Francia no nos irá a la zaga, cuando Nicolás Boileau escribe que "les climats font souvent les diverses humeurs", Nicolás Malebranche "que l'air qu'on respire cause aussi quelque changement dans les sprits", y, por fin, Blas Pascal para el que "no hay nada justo o injusto que no cambie su cualidad cuando cambia el clima".

Todo esto me hace pensar que Cervantes ha leído en el Examen una determinada teoría de los humores, así como una doctrina de los ingenios, que vienen a abundar en algo que era opinión común de la Europa de aquel tiempo. De acuerdo a la cual la "complexión" o constitución física estaba determinada por el equilibrio de las cuatro 
cualidades elementales (seco, húmedo, frío y caliente). Estas, junto a otros tantos humores del cuerpo (sangre, flema, bilis amarilla o cólera, y bilis negra o melancolía) condicionaba el temperamento o manera de ser. De ahí que los rasgos físicos de Don Quijote coincidan con la definición tradicional del individuo colérico. Y, por extensión, piense que los humores han configurado la idiosincrasia de los pueblos, como en el pasaje en el que confunde dos rebaños de ovejas con sendos ejércitos prestos a batirse en la llanura:

-A este escuadrón frontero -comenzó a decir Don Quijote- forman y hacen gentes de diversas naciones: aquí están los que beben las dulces aguas del famoso Xanto; los montuosos que pisan los masílicos campos, los que criban el finísimo y menudo oro en la felice Arabia; los que gozan las famosas y frescas riberas del claro Termodonte...

— ¡Váleme Dios, -respondió Sancho Panza-, y cuántas provincias dijo, cuántas naciones nombró, dándole a cada una, una maravillosa presteza, os atributos que le pertenecían, todo absorto y empapado en lo que había leído en sus libros mentirosos".

Asimismo, la pista melancólica que lleva a padecer una enfermedad del alma al caballero andante cervantino, se puede rastrear en la novela ejemplar El Licenciado Vidriera. La enajenación pasajera del personaje Tomás Rodaja, enlaza con los exempla de Sebastián Brant en La nave de los necios (Basilea, 1494) y la sátira de Erasmo de Rotterdam en el Elogio de la locura (Basilea, 1509), ilustrados por los grabados de Hans Holbein y las pinturas de El Bosco. Sigue la estela de la literatura burlesca que lanza una mordaz condena a los médicos, como en el poemario Triunpho de la Locura de Hernán López de Yanguas: "Los secuaces de Galieno/cuando matan, cuando sanan/ siempre medran, siempre ganan,/sus trabajos bien se emplean;/ los enfermos devanean/y los médicos devanan/con dos pasos que pasean/dos mil presentes le manan...”. Andando el tiempo, por fin, testimonios reales y ficticios, reforzarán estas tesis mediante los ejemplos de locura vítrea que aparecen en la obra de René Descartes Meditaciones metafísicas. Y es que la sociedad mantenía una actitud ambigua frente a estos "espíritus destemplados": les marginaba, arrojándoles a la deriva del río de la vida, y les atraía porque, en el fondo, pensaban que eran hondamente sabios. Es por eso que en el encadenamiento sentencioso del licenciado, como no podía ser de otro modo en un paciente al que no encuentran remedio a su mal, tiene cabida el comentario satírico hacia los malos doctores:

"El juez nos puede torcer o dilatar la justicia; el letrado, sustentar por su interés nuestra injusta demanda; el mercader, chuparnos la hacienda; finalmente, todas las personas con quien de necesidad tratamos nos pueden hacer algún daño; pero quitarnos la vida sin quedar sujetos al temor de castigo, ninguno: sólo los médicos nos pueden matar y nos matan sin temor y a pie quedo, sin desenvainar otra espada que la de un récipe; y no hay descubrirse sus delitos, porque al momento los meten debajo de la tierra".

Por consiguiente, hay veces, que San Juan y Cervantes coinciden porque beben en lo mismos tópicos renacentistas, como por ejemplo, en la afirmación de que cada uno es hijo de su tiempo. Esta máxima, usada desde Santa Teresa de Jesús hasta Fray Luis de León, se recoge en el Examen: "Cuando el hombre hace algún hecho heroico o alguna extraña virtud o hazaña, entonces nace de nuevo... y ahora se llama hijo de sus obras". Y se repite en El Quijote: "Importa poco eso, que Haldudos pueden ser caballeros, cuanto más que cada uno es hijo de sus obras".

Sin embargo, en otros casos, aún siendo un tema común a la cultura áurea, cual es el caso de la defensa de las lenguas vulgares, se observa más nítidamente cómo el escritor ha leído y asimilado el trabajo del médico. Dice el doctor el año de 1575 en el capítulo VIII del Examen:

"De ser las lenguas un plácito y antojo de los hombres, y no más, se infiere claramente que en todas se pueden enseñar las ciencias, y en cualquiera, se dice y declara lo que la otra quiso sentir. Y así, ninguno de los graves autores fue a buscar lengua extranjera para dar a entender sus conceptos; antes los griegos escribieron en griego, los romanos en latín, los hebreos en hebraico, y los moros en arábigo; y así hago yo en mi español, por saber mejor esta lengua que otra ninguna" 
Y el novelista reitera el año de 1616 en el capítulo XVI de la segunda parte de $E l$ Quijote:

"El grande Homero no escribió en latín, porque era griego; ni Virgilio escribió en griego, porque era latino. En resolución, todos los poetas antiguos escribieron en la lengua que mamaron en la leche, y no fueron a buscar las extranjeras para declarar la alteza de sus conceptos; y siendo esto así, razón sería se extendiese esta costumbre por todas las naciones, y que no se desestimase el poeta alemán porque escribe en su lengua, ni el castellano que escribe en la suya".

En suma, Cervantes conocía bien la obra huertiana, aplicando alguna de sus teorías a su producción novelística. Mas de ahí a considerar la constante lectura del Examen de ingenios como motor de su creación literaria, media un abismo, el mismo que existe entre la duda razonable y la hipérbole bienintencionada. Porque, al fin y al cabo, que el literato barroco leyese al médico renacentista, era lógico en unos escritores que tenemos por ingenios de su tiempo. La ley universal que nos hace a todos ser hijos de nuestras obras.

Madrid, enero 2009

\section{RECOPILACIÓN BIBLIOGRÁFICA}

\section{Ediciones del Examen de ingenios}

HUARTE DE SAN JuAn, Juan (1593): Examen de ingenios para las sciencias : donde se muestra la difere[n]cia de habilidades, que ay en los hombres y el genero de las letras que a cada vno responde en particular; S.1.: En la Oficina Plantiniana.

(1698) Examen des esprits propres et naiz aux sciences... ; Paris, M. Somnius.

(1884) Examen de ingenios para las ciencias; Barcelona: Biblioteca Clásica Española.

(1946) Examen de Ingenios para las Ciencias; $2^{\mathrm{a}}$ ed; Madrid: Espasa Calpe, D.L.

(1930) Examen de ingenios para las ciencias; Edición comparada de la préncipe (Baeza, 1575) y sub-prencipe (Baeza, 1594) Prólogo, sumarios, notas y preparación por Rodrigo Sans; Madrid: [s.n.], Imp. La Rafa

(1944) Doctor Huarte de San Juan: antología; selección y prólogo de Emiliano Aguado; Madrid: FE.

\section{Otras Obras de referencia}

Actas de las II Jornadas de Hispanismo Filosófico: http://filosofia.org/rev/bas/bas22106.htm (12-09-06; 13:01) [Recurso Electrónico]

Aguado, Emiliano [ed.] (1944): Doctor Huarte de San Juan; Madrid : Fe (Uguina)

BARTra, Roger (2001): Cultura y melancolía. Las ENFERMEDADES del alma en la España del Siglo de Oro. BARCELONA, Anagrama.

Beltrán, Miquel (1997): «Huarte de San Juan y Spinoza: consideraciones sobre el vulgo y la filosofía natural», en: Pensamiento: Revista de investigación e Información filosófica, ISSN 0031-4749, Vol. 53, No 205, pags. 53-64

Biurrun LizARAZu, José Javier (1996): “Huarte de San Juan: vida y obra en el contexto político y religioso de la España del siglo XVI", en: El Basilisco: Revista de filosofía, ciencias humanas, teoría de la ciencia y de la cultura, ISSN 0210-0088, $\mathrm{N}^{\circ} 21$, pags. 16-17.

Borges Guerra, Mónica; García Moreno, Patrocinio; León del Río, Rafael (1999): "La neuropsicología del renacimiento: examen de ingenios de Juan Huarte de San Juan", en: Revista española de neuropsicología, ISSN 1139-9872, Vol. 1, No. 1, pags. 63-89.

Bustamante-Martínez, C.; Martín Araguz, Antonio (2004): "Examen de ingenios, de Juan Huarte de San Juan, y los albores de la Neurobiología de la inteligencia en el Renacimiento español", en: Revista de neurología, ISSN 0210-0010, Vol. 38, No. 12, pags. 1176-1185.

Calatayud Buades, Luis (s.a.): La Pedagogía y los clásicos españoles: Simón de Abril - Huarte de San Juan Saavedra Fajardo - Sabuco de Nantes; Madrid: Juan Puedo.

Castro, Adolfo de [et alt.] (1953): Obras escogidas de filósofos; Madrid: Atlas.

Centro Cisneros. Breve reseña sobre la vida de Juan Huarte de San Juan: http://www.centrocisneros.uah.es/ galpersons.asp?pag=personajes\&id=75 (12-09-06; 13:01) [Recurso electrónico]

Centro Virtual Cervantes. Descripción catalográfica de la obra Examen de ingenios (italiano) de Juan Huarte de San Juan. http://cvc.cervantes.es/obref/fortuna/expo/literatura/lite032.htm (18-09-06; 12:38) [Recurso electrónico] 
Cervantes VIRTUAL: http://www.cervantesvirtual.com/FichaAutor.html?Ref=304 [Recurso electrónico]

Chappuys, GABRIEl [trad.] (1608): Anacrise, ou Parfait jugement et examen des esprits propres et nez aux sciences ; Lyon, J. Didier.

Chicharro Chamorro, Rogelio (2004): La ciudad de Baeza en la época de Huarte de San Juan; Alicante: Fundación para la Creación de Empleo Juan Huarte de San Juan.

Chóliz Montañés, Mariano; Ferragud, A.; Gómez Iñiguez, Consolación (2001): «El ingenio: Las obras de Ignacio Rodríguez de San José y Huarte de San Juan", en Revista de historia de la psicología, ISSN 0211-0040, Vol. 22, $\mathrm{N}^{\mathrm{o}} 3-4$, pag. 351.

Cibernous, página de Filofía en la Red: http://www.cibernous.com/autores/biedma/teoria/filrenac/huarte.html, (12-09-06; 13:01) [Recurso electrónico]

III Congreso General de Historia de Navarra, Pamplona, 19-24 septiembre 1994. Area II: El mundo de las ideas Ponencia: Corrientes educativas europeas en la educación navarra: LA CREATIVIDAD LINGÜÍSTICA EN HUARTE DE SAN JUAN Y NOAM CHOMSKY. http://www.unav.es/users/Articulo33.html (18-09-06; 12:36) [Recurso Electrónico]

Corpas, JuAn RAMón (2003): Examen de ingenios para las ciencias; Pamplona: Ediciones y Libros.

Duché-Gavet, Véronique (2003): Juan Huarte au XXIe siècle: actes de colloque; Actes du Colloque International "Juan Huarte au XXIe siècle», 27-28 mars 2003, Faculté de Bayonne-Mairie de Saint-Jean-Pied-de-Port.

Etxarren Lohigorri, J. B. (1975): Huarte, hator etxerat; Oiñati (Guipúzcoa): Edit. Franciscana Aranzazu.

Farinelli, Arturo (1936): Dos excéntricos: Cristóbal de Villalón, el Dr.Juan Huarte; s.n.; Madrid: Imp. de la Lib. y Casa Edit.

Franzbach, Martin (1965): Lessings Huarte-šbersetzung (1752): Die Rezeption und Wirkungsgeschichte des "Examen de Ingenios para las Ciencias" (1575) in Deutschland; Hamburg : Kommissions Verlag: Cram, De Gruyter \& Co.

FranzBaCh, MARTIN (1978): La traducción de Huarte por Lessing (1752) : recepción e bistoria de la influencia del "Examen de Ingenios para las Ciencias" (1575) en Alemania; traducción del alemán por Luis Ruiz Hernández; Pamplona: Diputación Foral de Navarra, Institución Príncipe de Viana, Consejo Superior de Investigaciones Cientificas.

Fresco OTERo, Felisa [ed.] (1991): Examen de Ingenios para las Ciencias. Juan Huarte de San Juan; Madrid: Espasa Calpe, D.L.

García García, Emilio; Miguel Alonso, Aurora (2003): «El Exámen de Ingenios de Huarte de San Juan en la Bibliotheca Selecta de Antonio Possevino", en: Revista de bistoria de la psicología, ISSN 0211-0040, Vol. 24, No 3-4, pags. 387-396.

García García, Emilio; Miguel Alonso, Aurora (2004): "El "Examen de ingenios" de Huarte en Italia. La "Anatomía ingeniorum" de Antonio Zara", en: Revista de historia de la psicología, ISSN 0211-0040, Vol. 25, No 4, pags. 83-94.

García Vega, Luis (1988): Juan Huarte de San Juan (¿1529?-¿1588?); $1^{\mathrm{a}}$ ed.; Madrid: Ediciones del Orto.

(1989) Carácter utópico-científico del "Examen de Ingenios" de Juan Huarte de San Juan", en: Psicología e historia: contribuciones a la investigación en bistoria de la psicología / coord. por Enrique Lafuente Niño, José Quintana, Alberto Rosa Rivero, ISBN 84-7477-182-X, pags. 83-96

García Vega, Luis [et atl.] (1991): Juan Huarte de San Juan: patrón de la psicología española; Madrid: Edicions académicas, D.L.

Gauro, Miguel (1984): Estudio de la obra del Doctor Huarte de San Juan; Salamanca: Ediciones Universidad de Salamanca, D.L.

Granjel, Luis S. (1988): Juan Huarte y su “Examen de ingenios»; Salamanca: Academia de Medicina.

Gratit, Salustio [trad.]; Gagliardelli, Domenico [notas] (1604): Essamina de gl'ingegni de gli huomini accomodat ad apprendere quai si voglia scienza. Di Giovanni Huarte. Nella quale, manifestandosi la diversità delle nature loro...Dalla lingua castigliana tradotta in pura italiana da Sal.[ustio] Grat.[ii]. Con annotationi...di Domenico Gagliardelli... / Examen de ingenios para las ciencias; Venetia, appresso Barezzo Barezzi.

Herrero Porras, Antolín (1941): Juan Huarte de San Juan: Examen de ingenios para las ciencias...; Madrid: [El] Magisterio Español.

Iriarte, M. de (1939): El Doctor Huarte de San Juan y su examen de Ingenios: contribución a la Historia de Psicología Diferencial; Madrid: Jerarquía.

(1940) El Doctor Huarte de San Juan y su Examen de ingenios: Contribución a la Historia de la Psicologia diferencial; Madrid: Aldus: Edic. Jerarquia,

(1948) El Doctor Huarte de San Juan y su examen de Ingenios: contribución a la Historia de Psicología Diferencial; 3a ed. corr.; Madrid: Consejo Superior de Investigaciones Científicas. 
(1948) El Doctor Huarte de San Juan y su "Examen de ingenios". Contribución a la Historia de la Psicología diferencial; $3^{a}$ ed. corr.; S.1.: s.n.; Madrid: Imp. Vda. de Juan Puedo.

JuNTA DE ANDALUCíA: http://www.juntadeandalucia.es/averroes/concurso2004/ver/01/culturandaluza/12huarte.htm (18-09-06; 12:41) [Recurso Electrónico]

López Piñero, José María (2004): "Juan Huarte de San Juan: La psicología diferencial y el cerebro", en: Mente y cerebro, ISSN 1695-0887, N.9, pags. 6-9

MondéJar, José (1984): «El pensamiento lingüístico del doctor Juan Huarte de San Juan", en Revista de Filología Española, $\mathrm{n}^{\circ}$ 64; p. 71-128.

Moya, J.; García Vega, Luís (1990): "Juan Huarte de San Juan: the father of the Diferencial Psychology", en: Revista de bistoria de la psicología, ISSN 0211-0040, Vol. 11, N $\mathrm{N}^{\circ}$ 1-2 (Ejemplar dedicado a: La historia de las Mujeres en Europa: revisión teórica y metodológica), pags. 123-158

Müller, Cristina (2002): Ingenio y melancolía: una lectura de Huarte de San Juan; traducción del francés: Manuel Talens y María Pérez Harguindey; Madrid: Biblioteca Nueva.

Pérouse, Gabriel-A. (1970): L'Examen des esprits du Docteur Juan Huarte de San Juan: la diffusión et son influence en France ause XVIe. et XVIIe. Siècles; Paris: Les Belles Lettres.

Peset Reig, José Luís (2000): "Las críticas a la Universidad de Juan Huarte de San Juan», en: Las universidades bispánicas: de la monarquía de los Austrias al centralismo libera : V Congreso Internacional sobre Historia de las Universidades Hispánicas, Salamanca, 1998 / coord. por Luis Enrique Rodríguez San Pedro Bezares, Vol. 1, ISBN 84-7846-931-1, pags. 387-396

Porqueras Mayo, Alberto; Laurenti, Joseph L. (1989): «La colección de Huarte de San Juan en la biblioteca de la Universidad de Illinois (ediciones de los siglos XVI y XVII): notas hacia un estudio del impácto internacional de Huarte de San Juan", en: Homenaje al profesor Ignacio Elizalde: estudios literarios / coord. por Roberto Pérez, ISBN 84-7485-114-9, pags. 251-267.

Rincón González, Ma Dolores (2004): “Juan Huarte de San Juan (1529?-1588?)», en: Universitarios giennenses en la Historia: apuntes bibliográficos / coord. por Vicente Salvatierra Cuenca, Pedro Antonio Galera Andreu, ISBN 84-8439-205-8, pags. 91-109

Quintana Fernández, J. (2001): "Los orígenes de la "Tradición española del ingenio”, en: Revista de historia de la psicología, ISSN 0211-0040, Vol. 22, No 3-4, pags. 505-516.

Read, Malcolm Kevin (1981): Juan Huarte de San Juan; Boston: Thayne Publ., cop.

Rey Altuna, Luis (1956): Juan Huarte de San Juan y su "examen de ingenios": valoración educativa actual; Bilbao: Publicaciones de la Junta de Cultura de Vizcaya.

SAlillas, Rafael (2003): Un gran inspirador de Cervantes, el Dr. Juan Huarte y su examen de ingenios; Pamplona (Navarra): Analecta.

Salinas Quijada, Francisco (1969): Juan Huarte de San Juan; Pamplona: Diputación Foral de Navarra, Dirección de Turismo, Bibliotecas y Cultura Popular, D.L.

(1978) Juan Huarte de San Juan; $2^{\mathrm{a}}$ ed.; Pamplona: Diputación Foral de Navarra, Dirección de Turismo, Bibliotecas y Cultura Popular, D.L.

(1983) Juan Huarte de San Juan; $3^{\mathrm{a}}$ ed.; Pamplona: Diputación Foral de Navarra, Dirección de Turismo, Bibliotecas y Cultura Popular.

SANZ, Rodrigo (1930): Examen de ingenios para las ciencias. Juan Huarte de San Juan; Madrid: Imprenta La Rafa.

Serés, Guillermo (1989): Examen de Ingenios para las ciencias. Juan Huarte de San Juan; Madrid: Cátedra, D.L.

(1989) Examen de ingenios para las ciencias; Madrid: Cátedra, D.L.

(1996) Examen de ingenios para las ciencias; Barcelona: Círculo de Lectores.

(2005) Examen de ingenios para las ciencias; Madrid: Cátedra.

Symploké. Enciclopedia Filosófica. Artículo: Juan Huarte de San Juan: http://symploke.trujaman.org/index. php?title=Juan_Huarte_de_San_Juan (18-09-06; 12:40) [Recurso Electrónico]

Torre, Estebán (1977): Examen de ingenios para las ciencias. Juan Huarte de San Juan; Madrid: Editora Nacional, D.L.

(1977) Ideas lingüísticas y literarias del doctor Huarte de San Juan; Sevilla: Servicio de Publicaciones de la Universidad.

(1984) Sobre lengua y literatura en el pensamiento científico español de la segunda mitad del siglo XVI: las aportaciones de G. Pereira, J. Huarte de San Juan y F. Sánchez El Escéptico; Sevilla: Servicio de Publicaciones de la Universidad.

(1988) Examen de ingenios para las ciencias; $1^{\text {a }}$ ed.; Barcelona: PPU

Velarde Lombraña, Julián (1993): "Huarte de San Juan, patrono de psicología", en: Psicothema, ISSN 0214-9915, Vol. 5, $\mathrm{N}^{\mathrm{o}}$. 2, 1993, pags. 451-458. 
Vion, ChaRles [trad.] (1645): [L']examen des esprits pour les sciences ou se monstrent les differences d'Esprits, qui se trouvent parmy les bommes, et à quel genre de science chacun est propre en particulier... Nouv. trad... Ipar Charles Vion, Sieur de Dalibray]; Paris, J. Le Bouc.

(1661) [L']examen des esprits pour les sciences... composé par Jean Huarte, médecin espagnol. Nouvellement traduit suivant l'ancien original [par Vion d'Alibray] et augmenté suivant la dernière impression d'Espagne; Paris, chez Jean Guignard le fils.

Virues-Ortega, Javier (2005): "Juan Huarte de San Juan y su influencia en la psicolingüística cartesiana y moderna: un encuentro con Noam Chomsky", en: Psicotbema, ISSN 0214-9915, Vol. 17, N. 3, pags. 436-440.

Virués Ortega, Javier; Buela Casal, Gualberto; Carpintero Capell, Heliodoro (2006): «Una aproximación a la vida de Juan Huarte de San Juan: los primeros años de práctica profesional (1560-1578)", en: Psicothema, ISSN 0214-9915, Vol. 18, No. 2, pags. 232-237

Vleeschauwer, H. J. De (1958): Autour de la classification psychologique des sciences: Juan Huarte de San Juan, Francis Bacon, Pierre Charren, D'Alembert ; Pretoria: Mousaion.

(1958) Autour de la classification psychologique des sciences: Juan Huarte de San Juan, Francis Bacon, Pierre Charren, D'Alembert; Pretoria: University of South Africa.

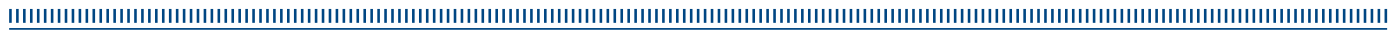

